Gut, 1981, 22, 207-212

\title{
Hyperplasia of the exocrine pancreas after small bowel resection in the rat*
}

\author{
P HAEGEL, C STOCK, $\dagger$ J MARESCAUX, B PETIT, AND J F GRENIER \\ From the INSERM, Unit 61, Biophysiopathology of the Intestine, Strasbourg, France
}

SUMMARY The effect of a $90 \%$ small bowel resection on the exocrine pancreas was investigated over a three month period in adult Wistar rats. Control animals underwent a sham-resection consisting of a transection and reanastomosis of the small intestine. After jejunoileal resection, the wet weight of the gland increased significantly $(52 \%)$ from the 15 th day. The parallel increase in total protein, DNA and RNA content without any modification in the ratios of pancreatic weight, protein, and RNA to DNA suggests that there is cellular hyperplasia but not hypertrophy. Small intestinal resection decreased significantly the amount of amylase when expressed per unit pancreatic weight; it reduced slightly but not significantly that of chymotrypsin, while it did not modify the amount of lipase. However, the total amount of these enzymes in the pancreas remained unaltered when compared with controls. It is concluded that a massive resection of the small bowel induces cellular hyperplasia in the rat exocrine pancreas; this could compensate the reduced level of enzymes in acinar cells.

After extensive small bowel resection, in man and animals, numerous changes occur in the remaining alimentary tract which help the organism adapt to the shortened intestine. There is mucosal hyperplasia with an increased number of epithelial cells per unit length of villus and an accelerated rate of epithelial cell renewal. ${ }^{1-5}$ There is also proliferation of parietal cells in the gastric glands. ${ }^{6}$ This latter effect has been generally ascribed to an increased level of gastrin in the plasma..$^{8}$ Exogenous gastrin and pentagastrin have been recognised to exert a trophic action upon the exocrine pancreas ${ }^{9-11}$ but do not affect the small bowel distal to the duodenum. ${ }^{12}$ Thus hypergastrinaemia induced by intestinal resection could alter the size and composition of the exocrine pancreas. Therefore it was of great interest to investigate the structural and biochemical changes of the rat pancreas over a three month period after a $90 \%$ excision of the small intestine.

\section{Methods}

One hundred and two male Wistar rats, weighing $290 \pm 5 \mathrm{~g}$, were randomly divided into two groups.

*This study was supported by the Institut National de la Santé et de la Recherche Médicale, France.

†Address for reprint requests: C Stock, INSERM, Unité de Recherches 61, Avenue Molière, 67200 Strasbourg, France.

Received for publication 14 October 1980
The first group (54 rats) served as sham-resected control animals and the second group (48 rats) underwent a $90 \%$ resection of the small bowel.

\section{OPERATIVE PROCEDURE}

After a 12 hour fast, a $90 \%$ jejunoileal resection was performed under ether anaesthesia. The peritoneal cavity was entered through a midline incision and the intestinal tract, from the ligament of Treitz to the ileocaecal junction, was exteriorised. The length of the combined jejunum and ileum, measured using slight tension, was nearly $100 \mathrm{~cm}$. Subsequently, $90 \%$ of the small intestine was removed beginning $5 \mathrm{~cm}$ distal to the ligament of Treitz. The remaining intestine was anastomosed by end-to-end enteroenterostomy using eight separate sutures of 6-0 silk. Sham-resections consisted of transection and reanastomosis of the small intestine either $5 \mathrm{~cm}$ below the ligament of Treitz or $5 \mathrm{~cm}$ from the ileocaecal junction. After surgery, the animals were weighed, then allowed tap water and fed a standard rat chow-diet ad libitum (UAR, ref. A 03, Villemoisson-sur-Orge, France). After a 12 hour fast, the animals of both groups were weighed and killed at two weekly intervals from 15 days to three months. At each period, the sham- and resected group consisted respectively of nine and eight animals. Food intake was measured at two day intervals before and after surgery. 
TISSUE SAMPLING AND WEIGHING PROCEDURES

The whole pancreas was rapidly removed from the rat, briefly washed in $\mathrm{NaCl} 0.9 \%$, and trimmed free of adherent fat and lymph nodes. After weighing of the gland, small samples were removed for electron microscopy while the remainder was homogenised at $4^{\circ} \mathrm{C}$ in distilled water in order to determine its protein content, DNA, RNA, and enzyme activities.

\section{BIOCHEMICAL STUDIES}

The activity of amylase was measured with 3,5dinitro-salicylic acid, using starch as substrate according to Danielsson..$^{13}$

The activities of lipase and chymotrypsin were measured titrimetrically using respectively an emulsion of olive oil ${ }^{14}$ and acetyltyrosine-ethylester ${ }^{15}$ as substrate.

Protein concentrations were determined according to the method of Lowry et al. ${ }^{16}$ with bovine albumin as a standard. DNA and RNA were extracted as described by Schneider. ${ }^{17}$ DNA was determined by the diphenylamine method using calf thymus DNA as a standard. ${ }^{18}$ RNA was determined by the orcinol method using yeast RNA as a standard. ${ }^{19}$

HISTOLOGY AND ELECTRON MICROSCOPY Samples of pancreatic tissue were fixed at $4^{\circ} \mathrm{C}$ in $2 \%$ glutaraldehyde buffered with $0.2 \mathrm{M}$ sodium cacodylate, $\mathrm{pH} 7 \cdot 4$, and postfixed in $1 \%$ osmilim tetroxide in the same buffer. They were then dehydrated in a graded sequence of alcohols and embedded in Araldite. Sections $0.5 \mu$ thick were stained with toluidine blue for light microscopy. Ultrathin sections were stained with uranyl acetate and lead citrate, then examined with a Philips EM 300 electron microscope.

STATISTICAL ANALYSIS

For each parameter, the mean and standard error of the mean were calculated; for group comparisons, Student's unpaired $t$ test was applied.

\section{Results}

FOOD INTAKE, BODY AND PANCREATIC WEIGHT

As shown in Fig. 1, rats subjected to a $90 \%$ small bowel resection rapidly lost $8 \%$ of their initial weight and maintained this reduced level for six weeks. From this period the animals gained weight progressively and reached control values between eight and 12 weeks.

Food intake, measured at two day intervals, before and after surgery, showed no difference between sham- and resected animals. However, during the 48 hours after surgery, the mean caloric intake diminished by $48 \%$ when compared with preoperative values; then it increased progressively and attained preoperative values from the sixth postoperative day.

Fig. 2 illustrates the evolution of the wet weight of the pancreas over the 12 week postoperative period. In sham-resected animals, it was approximately $682 \cdot 5 \pm 18 \cdot 3 \mathrm{mg}$ over the whole period. A $90 \%$ resection of the small intestine enhanced significantly $(\mathrm{P}<0.001)$ this parameter to an average value of $1008 \cdot 9 \pm 33 \cdot 3 \mathrm{mg}$. However this increase was more pronounced between two and six weeks $(52 \%)$ than between eight and 12 weeks (43\%).

\section{PROTEIN, DNA AND RNA CONTENT}

OF THE GLAND

As illustrated in Fig. 3, the total protein, DNA and RNA content of the pancreas increased after small bowel resection; the most marked increase was yet observed during the early postoperative period until six weeks.

As the amount of protein expressed per unit weight of tissue (Fig. 3) was the same in sham- and resected animals, it is suggested that the increased

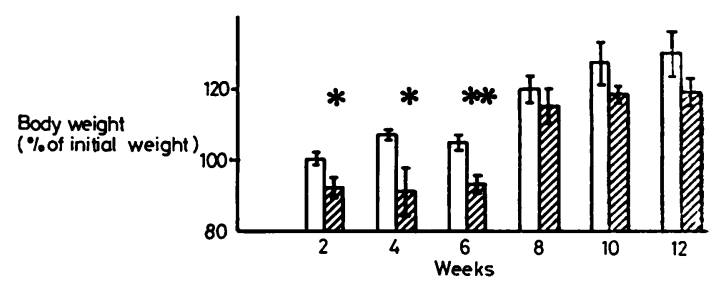

Fig. 1 Body weight over a 12 week period after intestinal-or sham-resection. Results are means $\pm S E M$ of nine animals after sham-resection (open bars) and eight animals after small bowel resection (hatched bars). ${ }^{*} \mathrm{P}<0.05$. ${ }^{* *} \mathrm{P}<0.01$.

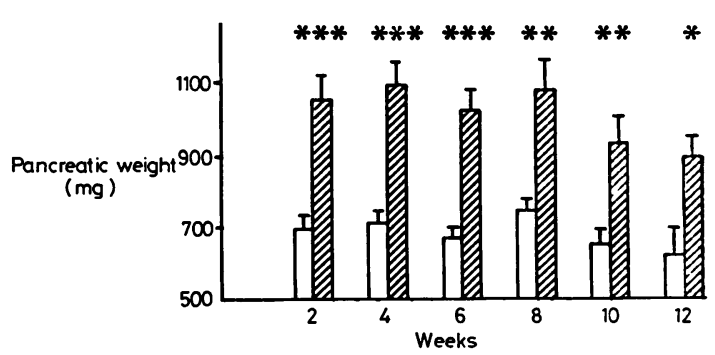

Fig. 2 Pancreatic wet weight over a 12 week period after intestinal- or sham-resection. Results are means $\pm S E M$ of nine animals after sham-resection (open bars) and eight animals after small bowel resection (hatched bars). ${ }^{*} \mathrm{P}<0.05 .{ }^{* *} \mathrm{P}<0.01{ }^{* * *} \mathrm{P}<0.001$. 


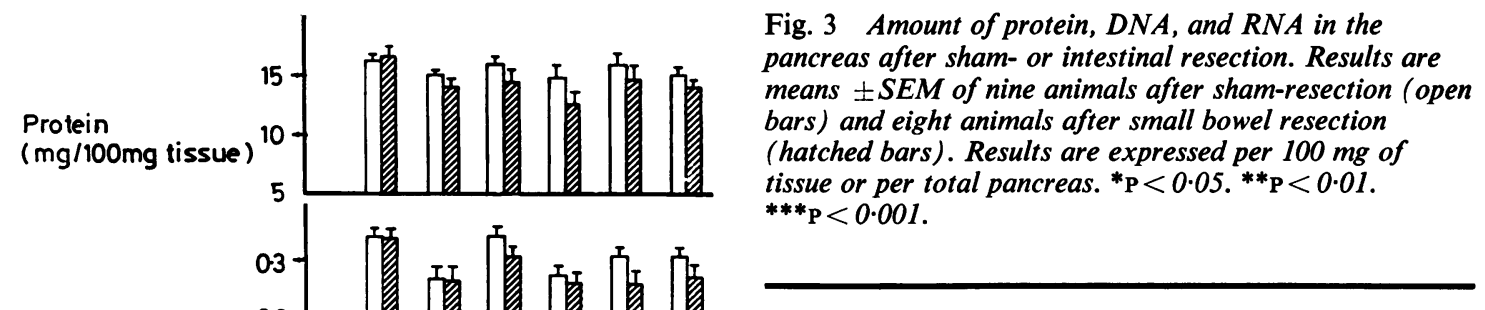

DNA (mg/100mg tissue)
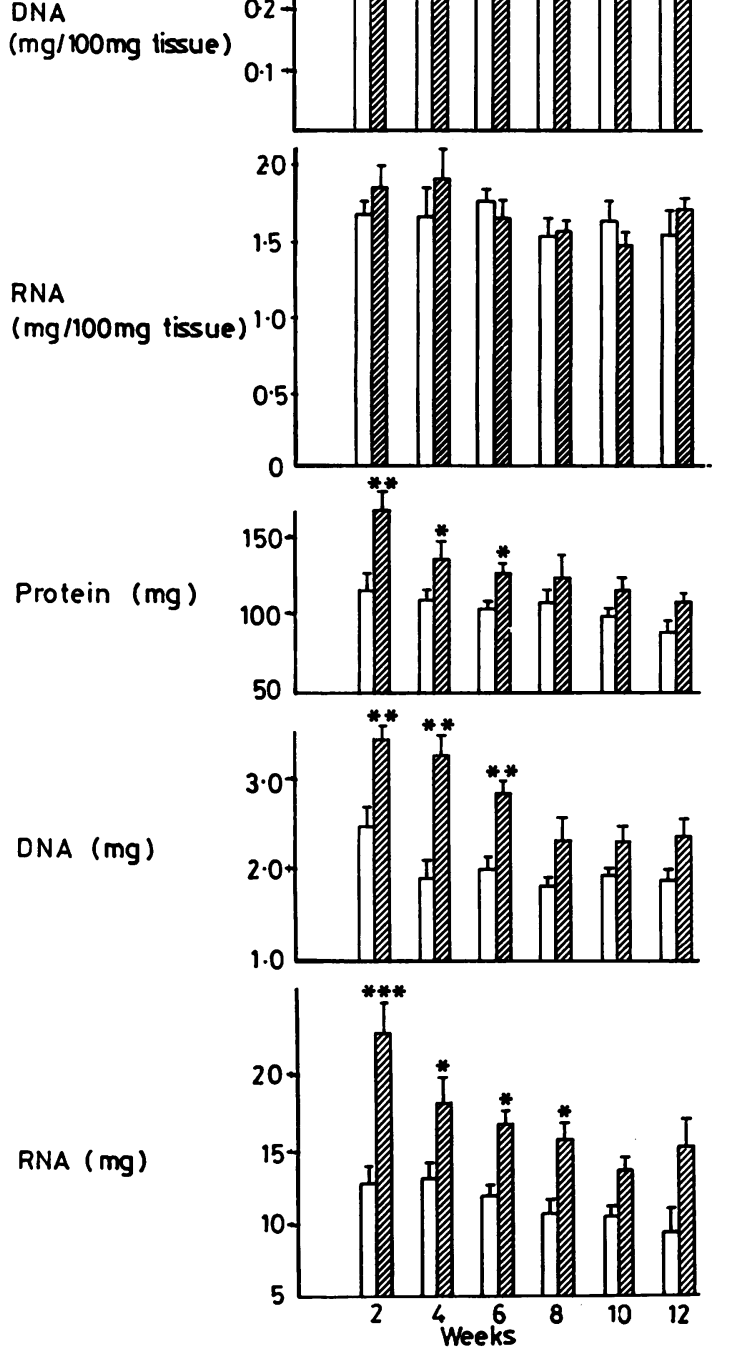

pancreatic weight after intestinal resection was not due to gain in water content.

The rise in total DNA content of the gland can be explained (1) by a greater number of cells in the gland, (2) by the appearance of polyploid cells, and (3) by the occurence of numerous mitoses in the gland. This latter hypothesis seems unlikely, as mitotic figures were observed only at the 15 day period after intestinal resection and were few in number. The second hypothesis is not confirmed by our biochemical data, as the amount of DNA expressed per $100 \mathrm{mg}$ of pancreatic tissue (Fig. 3) or per $\mathrm{mg}$ of protein (data not shown) was quite similar in both groups over the 12 week experimental period. Thus it appears that the increased pancreatic weight after small bowel resection reflects cellular hyperplasia. The ratios of RNA, protein and pancreatic weight to DNA are generally considered as indices of cellular hypertrophy; these ratios did not differ significantly in either the sham- or the resected group of animals; it is therefore suggested that cellular hyperplasia was not associated with cellular hypertrophy in the resected group of animals.

\section{ENZYME ACTIVITY OF PANCREACTIC TISSUE}

As shown in Fig. 4, the mean enzyme levels in the pancreatic tissue, when expressed per $100 \mathrm{mg}$ of tissue, were generally reduced after intestinal resection. There is a marked reduction of amylase content which was sustained and occurred earliest, while that of chymotrypsin was weak and not significant. The content of lipase, though varying somewhat over the 12 week period in sham- resected animals, was never affected by small bowel excision. However, as the size of the pancreases in resected animals increased, the mean total content of the three enzymes studied was approximately the same as that of the control animals.

\section{PANCREATIC HISTOLOGY AND}

ULTRASTRUCTURE

In toluidine-blue stained semi-thin sections, exocrine pancreatic tissue as well as islets of Langerhans were normal both in animals subjected to a shamand a small bowel resection. In electron microscopy, the distribution of zymogen granules in acinar cells varied considerably from one resected animal to another and even from one block of tissue of the same animal to another. However, in most cases, the number of zymogen granules was slightly reduced, while in a few others the gland was completely depleted of secretory granules. In these latter cases lipid droplets often accumulate in the basal part of the acinar cell cytoplasm. Mitotic figures have been 


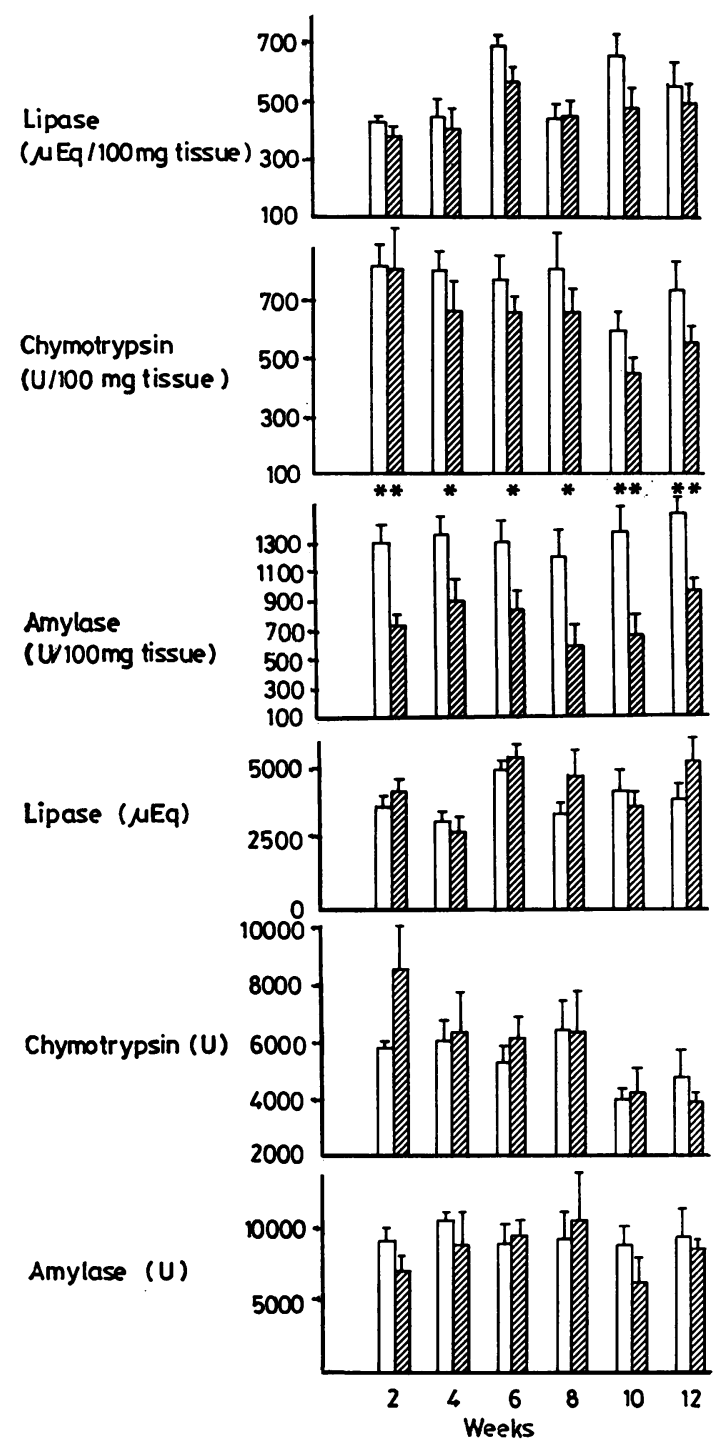

Fig. 4 Amount of amylase, chymotrypsin, and lipase in the pancreas after sham- or intestinal resection. Results are means $\pm S E M$ of nine animals after sham-resection (open bars) and eight animals after small bowel resection (hatched bars). Results are expressed per $100 \mathrm{mg}$ of tissue or per total pancreas. ${ }^{*} \mathrm{P}<0.05$. $* * \mathrm{P}<0.01$.

observed in acinar cells after small bowel resection, while they were absent in controls. Mitoses were never present in cells other than acinar cells and were seen only during the early postoperative period, until 15 days. Thus it is suggested that cellular hyperplasia, defined by biochemical methods, developed early after surgery and principally from acinar cells.

\section{Discussion}

The present study clearly indicates that a massive resection of the small bowel induces a marked increase of the pancreatic weight in rats. The striking parallel increase in total protein suggests that pancreatic growth could not be due to gain in water content. The rise of total DNA content indicates that there is cellular hyperplasia. According to our ultrastructural observations, hyperplasia develops from acinar cells. Indeed, mitotic figures have been described in these cells but not in ductular, centroacinar cells, or islets of Langerhans. Mitosis has only been observed at period 15 days. At this period, the rise of DNA in the gland is most pronounced; thus it seems likely that the factor responsible for cell division occurs immediately after operation.

It is well accepted that pancreatic composition and size are closely regulated by dietary factors. Starvation rapidly depresses pancreatic growth and protein, enzyme and RNA synthesis. ${ }^{20}$ Feeding maintains pancreatic size and composition, ${ }^{21}$ but at present it is conceded that gastrointestinal hormones released by feeding may be involved. ${ }^{22}$ In the present investigation, the mean caloric intake was quite similar after sham- or intestinal resection. Thus it is suggested that the adaptive growth of the pancreas after small bowel resection is due to qualitative or quantitative alterations of any 'pancreatropic' hormone released. It has been recognised, largely as a result of pharmacological studies, that several gastrointestinal hormones stimulate pancreatic growth. Cholecystokinin-pancreozymin (CCK-PZ) a hormone liberated after food intake, has been shown to produce cellular hypertrophy and hyperplasia in the rat pancreas. ${ }^{23-25}$ Caerulein, an amphibian skin decapeptide which is structurally and functionally related to CCK-PZ, has the same effect. ${ }^{26}$ Gastrin, which shares a common C-terminal pentapeptide with both former hormones, initiates also growth response in the pancreas. ${ }^{102728}$ Secretin, another hormone which regulates the secretory function in the exocrine pancreas, has trophic effects on the gland, ${ }^{26}$ but this was not proven by others. ${ }^{24}$ Among all these hormones, only the level of gastrin has been shown to be increased in the plasma of dogs submitted to a $75 \%$ small bowel resection.? According to Mayston and Barrowman, ${ }^{10}$ gastrin also decreases the specific activities of enzymes in the rat pancreas, particularly that of amylase, and this corresponds well to the present findings. Thus it is suggested that gastrin may be implicated in pancreatic hyperplasia after a massive small bowel resection in the rat. This hypothesis remains, however, to be confirmed elsewhere.

As the aetiological factor of pancreatic growth 
adaptation is still unknown, its physiological consequences may be discussed. It is well recognised that intestinal adaptation after small bowel resection may be influenced by a variety of factors including intraluminal nutrition and the presence of normal chyme, nervous factors, hormonal as well as local stimulators. ${ }^{5}$ Biliary and pancreatic secretions have also been shown to stimulate growth in ileal mucosa, ${ }^{29} 30$ even after jejunal resection. ${ }^{31}$ Thus, it must be accepted that pancreatic enzyme composition is well preserved after intestinal resection. Our present data agree well with this assumption. Indeed, specific activities of enzymes, especially of amylase, were reduced in the gland after small bowel resection, while the total enzyme content was unaltered. Thus acinar cell hyperplasia compensated for the decreased level of enzymes in each cell.

In conclusion, the present investigation indicates for the first time that a massive small bowel resection provokes hyperplasia not only in the stomach and the remaining intestine, but also in the exocrine pancreas.

We are grateful to Misses C Arnold and A Crovisier, and $\mathrm{Mr} \mathrm{A}$ Hoeltzel for their careful technical assistance.

\section{References}

${ }^{1}$ Dowling RH, Booth CC. Structural and functional changes following small intestinal resection in the rat. Clin Sci 1967; 32: 139-49.

${ }^{2}$ McDermott FT, Roundnew B. Ileal crypt cell population kinetics after $40 \%$ small bowel resection. Autoradiographic studies in the rat. Gastroenterology 1976; 70: 707-11.

${ }^{3}$ Hanson WR, Osborne JW, Sharp JG. Compensation by the residual intestine after intestinal resection in the rat. II. Influence of postoperative time interval. Gastroenterology 1977; 72: 701-5.

${ }^{4}$ Weser E, Hernandez MH. Studies of small bowel adaptation after intestinal resection in the rat. Gastroenterology 1971; 60: 69-75.

${ }^{5}$ Williamson RCN. Intestinal adaptation (Second of two parts). Mechanisms of control. N Engl J Med 1978; 298: 1444-50.

${ }^{6}$ Winborn WB, Seelig LL Jr, Nakayama H, Weser E. Hyperplasia of the gastric glands after small bowel resection in the rat. Gastroenterology 1974; 66: 384-95. ${ }^{7}$ Barros d'Sa AAB, Buchanan KD. Role of gastrointestinal hormones in the response to massive resection of the small bowel. Gut 1977; 18: 877-81.

${ }^{8}$ Buxton B. Small bowel resection and gastric acid hypersecretion. Gut 1974; 15: 229-38.

${ }^{9}$ Johnson LR. The trophic action of gastrointestinal hormones. Gastroenterology 1976; 70: 278-88.

${ }^{10}$ Mayston PD, Barrowman JA. The influence of chronic administration of pentagastrin on the rat pancreas. Q J Exp Physiol 1971; 56: 113-22.
${ }^{11}$ Reber HA, Johnson F, Deveney K, Montgomery C, Way LW. Trophic effects of gastrin on the exocrine pancreas in rats. $J$ Surg Res 1977 ; 22: 554-60.

${ }^{12}$ Oscarson JEA, Veen HF, Williamson RCN, Ross JS, Malt RA. Compensatory postresectional hyperplasia and starvation atrophy in small bowel: dissociation from endogenous gastrin levels. Gastroenterology 1977; 72: 890-5.

${ }^{13}$ Danielsson A. Technique for measuring amylase secretion from pieces of mouse pancreas. Anal Biochem 1974; 59: $220-34$.

${ }^{14}$ Marchis-Mouren G, Sarda L, Desnuelle P. Purification of hog pancreatic lipase. Arch Biochem Biophys 1959; 83: 309-19.

${ }^{15}$ Reboud JP, Ben Abdeljlil A, Desnuelle P. Variations de la teneur en enzymes du pancréas de rat en fonction de la composition des régimes. Biochim Biophys Acta 1962; 58: 326-37.

${ }^{18}$ Lowry $\mathrm{OH}$, Rosebrough NJ, Farr AL, Randall RJ. Protein measurement with Folin Phenol reagent. $J$ Biol Chem 1951; 193: 265-75.

${ }^{17}$ Schneider WC. Phosphorus compounds in animal tissues. I. Extraction and estimation of deoxypentose nucleic acid and of pentose nucleic acid. $J$ Biol Chem 1945; 161 : 293-303.

${ }^{18}$ Richards GM. Modifications of the diphenylamine reaction giving increased sensitivity and simplicity in the estimation of DNA. Anal Biochem 1974; 57: 369-76.

${ }^{19}$ Schneider WC. Determination of nucleic acids in tissues by pentose analysis. In: Colowick SP, Kaplan NO, eds. Methods in Enzymology. New York: Academic Press, 1957: 680-4.

${ }^{20}$ Webster PD, Singh M, Tucker PC, Black O. Effects of fasting and feeding on the pancreas. Gastroenterology 1972; 62: 600-5.

${ }^{1}$ Morisset JA, Black O, Webster PD. Effects of fasting, feeding and betanechol chloride on pancreatic microsomal protein synthesis in vitro. Proc Soc Exp Biol Med 1972; 140: 1308-14.

22 Johnson LR, Copeland EM, Dudrick SJ, Lichtenberger LM, Castro GA. Structural and hormonal alterations in the gastrointestinal tract of parenterally fed rats. Gastroenterology 1975; 68: 1177-83.

${ }^{23}$ Brants F, Morisset J. Trophic effects of cholecystokininpancreozymin on pancreatic acinar cells from rats of different ages. Proc Soc Exp Biol Med 1976; 153: 523-7.

${ }^{24}$ Fölsch UR, Winckler K, Wormsley KG. Influence of repeated administration of cholecystokinin and secretin on the pancreas of the rat. Scand J Gastroenterol 1978; 13: 663-71.

${ }^{25}$ Mainz DL, Black O, Webster PD. Hormonal control of pancreatic growth. J Clin Invest 1973; 52 : 2300-4.

${ }^{26}$ Solomon TE, Petersen H, Elashoff J, Grossman MI. Interaction of caerulein and secretin on pancreatic size and composition in rat. Am J Physiol 1978; 235 (6): E714-9.

${ }^{27}$ Mayston PD, Barrowman JA. Influence of chronic administration of pentagastrin on the pancreas in hypophysectomized rats. Gastroenterology 1973; 64: 391-9.

${ }^{28}$ Dembinski AB, Johnson LR. Growth of pancreas and gastrointestinal mucosa in antrectomized and gastrintreated rats. Endocrinology 1979; 105: 769-73. 
${ }^{20}$ Altmann GG. Influence of bile and pancreatic secretions on the size of the intestinal villi in the rat. $\mathrm{Am} \mathrm{J}$ Anat 1971; 132: 167-78.

${ }^{30}$ Williamson RCN, Bauer FLR, Ross JS, Malt RA. Contributions of bile and pancreatic juice to cell prolifer- ation in ileal mucosa. Surg 1978; 83: 570-6.

${ }^{31}$ Weser E, Heller T, Tawil T. Stimulation of mucosal growth in the rat ileum by bile and pancreatic secretions after jejunal resections. Gastroenterology 1977; 73: 524-9. 